\title{
The polymorphisms of protein-tyrosine phosphatase receptor-type delta gene and its association with pediatric asthma in the Taiwanese population
}

\author{
Shyh-Dar Shyur ${ }^{1,4}$, Jiu-Yao Wang ${ }^{2,4}$, Cherry Guan-Ju Lin ${ }^{3}$, Ya-Hsin Hsiao ${ }^{3}$, Ya-Huei Liou ${ }^{3}$, \\ Ying-Jye $\mathrm{Wu}^{3}$ and Lawrence Shih-Hsin $\mathrm{Wu}^{*, 3}$
}

\begin{abstract}
${ }^{1}$ Department of Pediatrics, Mackay Memorial Hospital, Taipei, Taiwan; ${ }^{2}$ Department of Pediatrics and Institute of Molecular Medicine, College of Medicine, National Cheng-Kung University, Tainan, Taiwan; ${ }^{3}$ Research Development Division, Vita Genomics Inc., Taipei County, Taiwan
\end{abstract}

We previously reported an association between genetic differences of pediatric asthma subtypes and a short tandem repeat (STR) marker, D9S286. It has been known that the protein-tyrosine phosphatase receptor-type delta (PTPRD) gene is located downstream of D9S286 and that the physical distance between them is about $0.25 \mathrm{Mb}$. We selected and conducted genotyping on 76 single-nucleotide polymorphisms (SNPs) that encircle the genomic region of PTPRD in Taiwanese children with or without asthma. A total of 996 subjects were divided into testing group (674 subjects) and validation group (322 subjects). The results were further validated with the third subject group (611 subjects) recruited from different geographical regions. After Bonferroni correction, 3 out of 80 SNPs were found to be strongly significant $(P<0.05 / 76=0.000658)$ in the allele frequency test. This association was confirmed by validation groups. The results indicate that polymorphisms of PTPRD are strongly associated with pediatric bronchial asthma in the Taiwanese population.

European Journal of Human Genetics (2008) 16, 1283-1288; doi:10.1038/ejhg.2008.79; published online 16 April 2008

Keywords: PTPRD; pediatric asthma; allergy; SNPs; association study

\section{Introduction}

A whole-genome linkage disequilibrium mapping study for asthma was conducted on 190 allergic and nonallergic asthma children in Taiwan. The initial association study was conducted using a phenotypic definition of 'asthma' that meets the criteria of diagnosis of asthma by physicians and that is currently under treatment. Marker-to-marker synergistic analysis indicated that six STR loci may play

*Correspondence: Dr LS-H Wu, Research and Product Development, Vita Genomics Inc., 7FI., No. 6, Sec.1, Jungshing Road, Wugu Shiang, Taipei County 248, Taiwan.

Tel: +886289769123 ext 7532; Fax: + 886289769523 ;

E-mail: lawrence.wu@vitagenomics.com

${ }^{4}$ These authors contributed equally to this work.

Received 17 October 2007; revised 7 March 2008; accepted 14 March 2008; published online 16 April 2008 important roles in asthma. D9S286, one of the six STR loci, was located on chromosome $9 \mathrm{p}$ arm and its physical distance from $\mathrm{p}$ terminus is $8.04 \mathrm{Mb}{ }^{1}$ Protein-tyrosine phosphatase receptor-type delta (PTPRD) gene is the closest gene to the D9S286 locus with a physical distance of 8.3$8.72 \mathrm{Mb}$ from chromosome $9 \mathrm{p}$ terminus (ref. NCBI map viewer, Homo sapiens Build 36).

Protein-tyrosine phosphatases (PTPases) play essential roles in the regulation of cell growth, proliferation, differentiation, metabolism, cell cycle, cell-cell communication, cell migration, gene transcription, ion channel activity, the immune response and survival. ${ }^{2}$ Transmembrane-type PTPase is a major subfamily of PTPases that contains extracellular regions composed of immuno (Ig)like and fibronectin type III (FN-III)-like domains. Human PTPRD is also known as human transmembrane PTPase 
delta (HPTP $\delta$ ). The full length of PTPRD gene includes an extracellular region containing three Ig-like and eight FNIII-like domains connected by a transmembrane peptide to an intracellular region with two PTPase domains, whereas another splicing variant lacks four of the eight FN-III-like domains. It has also been reported that some splicing variants of PTPRD lack nine amino acids at the junction of the second and third Ig-like domains or nine amino acids within the fifth FN-III-like domain. ${ }^{3}$

The purpose of this study was to evaluate the significance of PTPRD as an allergy or asthma-susceptibility gene. In this study, about 1500 subjects, including southern (Tainan) and northern (Taipei) Taiwanese children, were recruited. The genotype of PTPRD polymorphisms was performed in the first-recruited subject group, and the alleles with significant association were validated in two independently ascertained subject groups. The results indicate that polymorphisms of PTPRD are strongly associated with pediatric bronchial asthma in the Taiwanese population.

\section{Materials and methods}

\section{Sample composition and clinical evaluation}

Our study population consists of asthmatic children of age ranging from 3 to 12 years. The study protocol was approved by the Ethical and Clinical Trial Committee of National Cheng-Kung University Hospital and Mackay Memorial Hospital. An informed consent form was given to all participants or their guardian after answering a modified British Medical Society respiratory questionnaire, which is exactly the same as that of the European Community Respiratory Health Survey (ERCHS). These surveys have similar validity as ISAAC pertinent to the diagnosis and assessment of asthma. ${ }^{4,5}$ Pulmonary function was tested using standard methods, including spirometry, before and after the administration of two puffs of inhaled salbutamol (200 $\mu \mathrm{g}$ per puff). The definition of asthma must meet the following criteria: (1) a history of having wheezing and experiencing shortness of breath during or without concurrent respiratory infections, (2) chronic coughing for more than 1 month and being diagnosed by a physician for the presence of wheezing episode(s) and (3) positive bronchodilator test showing a $15 \%$ increase in FEV1. Nonasthma controls were defined as those without an asthma history as in criteria (1) or those who did not meet criteria (2). Other evaluations included skin prick tests for responsiveness to six common aeroallergens, a differential blood count (including total eosinophil count) and levels of total serum IgE, as well as IgE specific to house dust and mixed pollens, using the Unicap system (Pharmacia Diagnostic, Sweden). A positive skin test was defined as the presence of $\geqslant 1$ reaction with a wheal diameter $\geqslant 5 \mathrm{~mm}$. Total serum $\operatorname{IgE}$ was measured by solid-phase immunoassay (Pharmacia IgE EIA; Pharmacia
Diagnostics). Nonallergy group was defined as total serum IgE $<200$ and negative skin test. The subjects of group 1 (674 subjects) and group 2 (322 subjects) were recruited from National Cheng-Kung University Hospital during 2002-2003 and 2004, respectively. The third subject group (611 subjects) was recruited from MacKay Memorial Hospital and National Cheng-Kung University Hospital in 2006.

\section{DNA preparation}

Genomic DNAs were extracted from blood samples of the study subjects using the QIAamp DNA Blood kit (QIAGEN), according to the manufacturer's instructions. The extracted genomic DNAs were analyzed by agarose gel electrophoresis, quantified by spectrophotometer and stored at $-80^{\circ} \mathrm{C}$ until use.

\section{SNP genotyping}

The PTPRD gene has 35 exons spanning $416.68 \mathrm{~kb}$. We selected 72 SNPs within and near PTPRD gene to examine the genotyping association results. All SNP genotypings were performed using the Taqman ${ }^{\circledR}$ SNP genotyping assays (ABI). The primers and probes of the PTPRD SNPs were from the ABI assay on demand (AOD) kit. The SNPs were selected by even distribution in the genomic region of the PTPRD gene and using the Taqman ABI AOD kit (Supplementary Table 1). Reactions were carried out according to the manufacturer's protocol. The probe fluorescence signal detection was performed using the ABI Prism 7900 RealTime PCR System.

DNA fragments of the PTPRD gene containing wellknown coding region SNP (NCBI, SNP database) in exon7, exon13, exon14, exon16, exon17 and exon18 were amplified on the ABI 9700 thermal cycler using two pairs of forward and reverse primers. The sequences and the related information of primers are listed in Supplementary Table 2. The fragments of PCR products were sequenced using the ABI 3700 automatic sequencer, according to the manufacturer's protocols. The sequence data were analyzed by PolyPhred software to identify the potential SNP candidates. The potential SNPs were manually checked to ensure the presence of true SNPs and only those that confirmed SNP data were subjected to subsequent statistical analysis.

\section{Statistical analysis}

For identifying the association between asthma and asthma-related phenotype and SNPs in PTPRD, an evaluation, including allele frequency and genotype frequency, was performed by $\chi^{2}$ test. The haplotypes were constructed using HAP website information (http://research.calit2.net/ hap), which was based on the assumption of imperfect phylogeny. According to the results of haplotype analysis, the tag SNPs in each haploblock were selected. The association analyses for haplotype were performed by 
Monte Carlo simulation ${ }^{6}$ using the CLUMP program (http://www.mds.qmw.ac.uk/statgen/dcurtis/software.html) and the $\chi^{2}$-test.

\section{Results}

\section{Characteristics of study subjects}

A total of 674 DNA samples extracted from 251 nonasthma children and 423 asthmatic children were collected as group 1 and genotyping was performed on all selected SNPs. It was found that there was statistically significant difference in the distribution of characteristics of study subjects between asthma and nonasthma, as listed in Table 1 . The 322 subjects (including 42 asthmatic children and 270 controls) in group 2 were recruited from the same hospital as those in group 1 at a different time. The characteristics with statistically significant difference between case and control of a total of 996 subjects are shown in Table 1. Group 3 subjects (including 414 asthmatic children and 197 controls) were recruited from two different hospitals, and only asthma status and total serum IgE were evaluated by fulfilling earlier-described criteria. The results showed that asthma subjects had a higher level of total serum IgE than did nonasthma subjects in all casecontrol comparisons (Table 1). According to allergy phenotype, 674 subjects in group 1 were further divided into four subgroups, 337 allergic asthma, 86 nonallergic asthma, 113 allergy subjects without asthma and 138 nonallergy and nonasthma subjects.

\section{The SNPs of PTPRD gene associated with asthma}

Seventy-six SNPs were identified in the study subjects. The locations of these SNPs are shown in Supplementary Table 1. Six coding regions or near the coding regions of SNPs were not detected by direct sequencing (Supplementary Table 2), and two intron SNPs did not display polymorphism by Taqman genotyping (Supplementary Table 3) in our study population. After Bonferroni correction $(P$-value $<0.05 / 76=0.000658$ ), three SNPs (rs2279776, rs767674 and rs2175595) with significantly different frequencies between asthma and nonasthma children in testing allele and/or genotype were observed (Table 2 and Supplementary Table 3). The power to detect significant association was calculated by power for association with errors (PAWE; http://linkage.rockefeller.edu/pawe/). ${ }^{7,8}$ For example, rs2279776, given 423 cases and 251 controls, adjusts $P$-value $0.0456(=0.0006 \times 76)$ and data without error, and the power for allelic and genotypic tests was 0.97 and 0.94 , respectively.

\section{PTPRD polymorphism and asthma phenotype}

For evaluating the association between asthma phenotypes and PTPRD polymorphisms, genotype frequencies of SNPs were compared between (1) allergic asthma and allergy without asthma, (2) asthma without allergy subjects and healthy control subjects and (3) asthma and nonasthma subjects. The statistically significant or marginal significant SNPs are listed in Table 2. The distribution patterns of significant SNPs were not sporadic in each comparison. Three SNPs showed statistical significance in all three comparisons (rs2279776, rs767674 and rs2175595) after Bonferroni correction in some comparisons.

\section{PTPRD polymorphism and allergy phenotype}

For evaluating the association between allergy phenotypes and PTPRD polymorphisms, the genotype frequencies of SNPs were compared between (1) allergic asthma and asthma without allergy subjects, (2) allergy without asthma

Table 1 Demographic information of the study subjects

\begin{tabular}{|c|c|c|c|c|}
\hline & \multicolumn{2}{|c|}{674 subjects $\left(996\right.$ subjects $\left.^{\mathrm{a}}\right)$} & \multicolumn{2}{|c|}{611 subjects } \\
\hline & Asthma & Non-asthma & Asthma & Non-asthma \\
\hline \multicolumn{3}{|l|}{ Mast } & \multirow[t]{3}{*}{ - } & \multirow[t]{3}{*}{ - } \\
\hline Positive & $339(379)$ & $113(239)$ & & \\
\hline Negative & $84(96)$ & $138(282)$ & & \\
\hline \multicolumn{3}{|l|}{$\operatorname{Der} p$} & \multirow{3}{*}{ - } & \multirow[t]{3}{*}{ - } \\
\hline Positive & $343(380)$ & $104(220)$ & & \\
\hline Negative & $80(95)$ & $147(301)$ & & \\
\hline \multirow{3}{*}{$\begin{array}{l}\text { Der } f \\
\quad \text { Positive } \\
\text { Negative }\end{array}$} & & & \multirow[t]{3}{*}{ - } & \multirow[t]{3}{*}{ - } \\
\hline & $322(358)$ & $69(184)$ & & \\
\hline & $101(117)$ & $182(337)$ & & \\
\hline \multirow[t]{2}{*}{$\ln (\lg E)$} & \multicolumn{2}{|c|}{ Mean \pm Std } & \multicolumn{2}{|c|}{ Mean \pm Std } \\
\hline & $\begin{array}{c}6.0669 \pm 1.4602(6.0277 \pm 1.4530) \\
t \text {-test } P<0.0001\end{array}$ & $\begin{array}{c}4.5668 \pm 1.7499 \\
(4.3697 \pm 1.7231) \\
(P<0.0001)\end{array}$ & $\begin{array}{r}5.8062 \pm 1.4364 \\
t \text {-test } F\end{array}$ & $\begin{array}{l}4.3243 \pm 1.7579 \\
.0001\end{array}$ \\
\hline
\end{tabular}

${ }^{a} 996(674+322)$ subjects represented total group1 and group2 subjects, all subjects recruited from National Cheng-Kung University hospital during 2002-2004; - : no evaluation for this character. 
Table 2 Significant $(P</ \sim 0.05)$ results in SNPs genotype/allele by subgroups of asthma phenotype

\begin{tabular}{|c|c|c|c|c|c|c|}
\hline \multirow[b]{2}{*}{ SNP ID } & \multicolumn{2}{|c|}{$A A$ vs $N A$} & \multicolumn{2}{|c|}{$A N$ vs NN } & \multicolumn{2}{|c|}{ Asthma vs Non-asthma } \\
\hline & Genotype P-value & Allele P-value & Genotype P-value & Allele P-value & Genotype P-value & Allele P-value \\
\hline rs966924 & 0.0146 & 0.0165 & - & - & - & - \\
\hline rs3780336 & 0.0340 & 0.0141 & - & - & - & - \\
\hline rs1039336 & 0.0275 & 0.0081 & 0.0127 & 0.1685 & - & - \\
\hline rs 2279776 & 0.0009 & 0.0004 & 0.0674 & 0.0283 & 0.0006 & 0.0001 \\
\hline rs3803826 & - & - & 0.0974 & 0.0290 & - & - \\
\hline rs4742500 & - & - & 0.0262 & 0.0611 & 0.0123 & 0.0627 \\
\hline rs 2281747 & - & - & - & - & 0.0457 & 0.0170 \\
\hline rs767674 & 0.0008 & 0.0001 & 0.0288 & 0.0066 & 0.0016 & 0.0002 \\
\hline rs13294631 & 0.0268 & 0.0098 & - & - & - & - \\
\hline rs11788439 & - & - & 0.0182 & 0.0095 & - & - \\
\hline rs 12685150 & - & - & 0.0011 & 0.0011 & - & - \\
\hline rs 2175595 & 0.0002 & 0.0001 & 0.0300 & 0.0065 & $<0.0001$ & $<0.0001$ \\
\hline rs1415723 & - & - & 0.0382 & 0.0060 & - & - \\
\hline rs10815923 & - & - & 0.0388 & 0.0153 & - & - \\
\hline rs1368982 & - & - & 0.1283 & 0.0344 & - & - \\
\hline rs 1434249 & - & - & 0.0023 & 0.0276 & 0.0190 & 0.2225 \\
\hline rs6477331 & - & - & 0.0045 & 0.0228 & & \\
\hline rs 2033555 & - & - & - & - & 0.1526 & 0.0485 \\
\hline rs723145 & 0.0654 & 0.0184 & - & - & 0.0754 & 0.0215 \\
\hline
\end{tabular}

AA: asthma with allergy; AN; asthma without allergy; NA: nonasthma with allergy; NN: nonasthma without allergy. The genotypic test results of asthma vs nonasthma were selected from Supplement Table 3.

and healthy control subjects and (3) allergy and nonallergy subjects. The statistically significant or marginally significant SNPs are listed in Table 3. Although there is not a single SNP displaying statistically significant difference in all three comparisons after Bonferroni correction, nevertheless, the distribution patterns of significant SNPs were not sporadic in each comparison.

\section{Haplotypes constructed by tag-SNPs of PTPRD gene region associated with asthma}

Seventy-six SNP loci were selected in constructing haplotypes using the method of imperfect phylogeny. The haplotypes of 18 haploblocks were presented by tag-SNP (tSNP) and are shown in Supplementary Table 4 . The tSNPs were general HAP (website mentioned) as described in the Materials and methods section shown in Supplementary Table 3. Blocks 4, 11, 15 and 17 were each presented by only one SNP. To evaluate haploblock associated with the difference between case and control, the haplotype frequencies between the two groups were tested by $\chi^{2}$-test and the very rare haplotypes were not included in the statistical test. Blocks 4, 5, 7, 12 and 17 showed statistical significance and the $P$-values were $7.8 \times 10^{-5}, 0.0294$, $2.2 \times 10^{-6}, 4.0 \times 10^{-8}$ and 0.0403 , respectively. Common haplotypes (frequency $>1 \%$ ) of all the haploblocks were subjected to $2 \times 2 \chi^{2}$-test (compared to sum of other haplotypes) and the results are listed in Supplementary Table 4. The haplotype(s) of haploblocks 4, 5, 6, 7, 12, 13 and 17 showed significantly $(P<0.05)$ different frequencies between asthma and nonasthma groups.

\section{Validation of the strongest association for asthma phenotype}

The SNPs rs2279776 (in exon27), rs767674 (in intron 20) and rs2175595 (in intron 4) showed significantly different allele and genotype frequencies after Bonferroni correction between asthma and nonasthma subjects. For validating the results described above, genotyping of the three strongly associated SNPs for group 2 and group 3 subjects was performed. It showed that SNP rs2279776 displayed statistical significance or marginal significance in both groups. Validation also showed that all three SNPs have statistical significance in the comparison of total subjects (Table 4). The odds ratio analysis showed that the risk genotypes of rs2279776, rs767674 and 2175595 were $\mathrm{CC}+\mathrm{GG}, \mathrm{GG}+\mathrm{AG}$ and TT, respectively (Table 5). Some conflict results, such as rs2279776 in 311 subjects, may be due to the small sample size or sampling bias. The genotype frequencies of rs767674 in individual patient groups differ from each other, but the frequencies of GG + AG genotype of case are higher than those of control in every study group (Table 5).

\section{Discussion}

In the current study, we investigated asthma and allergy phenotypes. After analysis and Bonferroni correction, it revealed that the testing polymorphism of PTPRD is associated with asthma but not with allergy phenotype. We found that the association between allergy phenotype and PTPRD polymorphism was significant before Bonferroni correction. It is not clear if PTPRD polymorphism is really associated with the general allergic state. The 
Table 3 Significant $(P</ \sim 0.05)$ results in SNPs genotype/allele by subgroups of allergy phenotype

\begin{tabular}{|c|c|c|c|c|c|c|}
\hline \multirow[b]{2}{*}{ SNP ID } & \multicolumn{2}{|c|}{$A A$ vs $A N$} & \multicolumn{2}{|c|}{$N A$ vs $N N$} & \multicolumn{2}{|c|}{ Allergy vs Non-allergy } \\
\hline & Genotype P-value & Allele P-value & Genotype P-value & Allele P-value & Genotype P-value & Allele P-value \\
\hline rs996924 & - & - & 0.0351 & 0.0390 & - & - \\
\hline rs3780336 & - & - & 0.0626 & 0.0267 & - & - \\
\hline rs1039336 & 0.0296 & 0.2466 & 0.0185 & 0.0082 & - & - \\
\hline rs1359119 & - & - & 0.0333 & 0.0585 & 0.0396 & 0.0251 \\
\hline rs2296100 & - & - & 0.0434 & 0.0933 & 0.0802 & 0.0563 \\
\hline rs767674 & - & - & - & - & 0.0033 & 0.0010 \\
\hline rs6477311 & - & - & 0.0054 & 0.0053 & 0.0548 & 0.0481 \\
\hline rs3763653 & - & - & - & - & 0.0424 & 0.0251 \\
\hline rs13293506 & - & - & 0.0580 & 0.0215 & - & - \\
\hline rs12685150 & 0.0113 & 0.0029 & - & - & - & - \\
\hline rs1415723 & 0.0837 & 0.0261 & - & - & - & - \\
\hline rs7041298 & - & - & 0.0119 & 0.0923 & - & - \\
\hline rs10815923 & 0.0518 & 0.0137 & - & - & - & - \\
\hline rs1434249 & 0.0611 & 0.0300 & - & - & 一 & - \\
\hline rs6477331 & 0.0409 & 0.0337 & - & - & - & - \\
\hline rs3887368 & - & - & 0.0005 & 0.0607 & 0.0165 & 0.1130 \\
\hline
\end{tabular}

AA: asthma with allergy; AN; asthma without allergy; NA: nonasthma with allergy; NN: nonasthma without allergy.

Table 4 Statistical analyses of three independent subject groups for SNPs rs2279776, rs767674 and rs2175595

\begin{tabular}{|c|c|c|c|c|c|c|c|c|c|}
\hline \multirow[b]{2}{*}{ SNP ID } & \multirow[b]{2}{*}{ Genotype } & \multicolumn{2}{|c|}{674 subjects } & \multicolumn{2}{|c|}{322 subjects } & \multicolumn{2}{|c|}{611 subjects } & \multicolumn{2}{|c|}{ Total } \\
\hline & & Case & Control & Case & Control & Case & Control & Case & Control \\
\hline \multirow[t]{4}{*}{ rs2279776 } & $\mathrm{CC}$ & 97 & 31 & 3 & 22 & 31 & 20 & 131 & 73 \\
\hline & CG & 199 & 116 & 19 & 137 & 200 & 73 & 417 & 326 \\
\hline & GG & 126 & 102 & 30 & 111 & 183 & 104 & 339 & 317 \\
\hline & & $\chi^{2}=14.8081$ & $P=0.0006$ & $\chi^{2}=4.8708$ & $P=0.0875$ & $\chi^{2}=7.0149$ & $P=0.0300$ & $\chi^{2}=10.2486$ & $P=0.0060$ \\
\hline \multirow[t]{4}{*}{ rs767674 } & AA & 88 & 77 & 20 & 112 & 151 & 76 & 259 & 265 \\
\hline & AG & 188 & 116 & 23 & 119 & 195 & 8 & 40 & 3 \\
\hline & GG & 143 & 57 & 9 & 39 & 68 & 36 & 220 & 132 \\
\hline & & $\chi^{2}=12.8969$ & $P=0.0016$ & $\chi^{2}=0.3370$ & $P=0.8449$ & $\chi^{2}=0.8828$ & $P=0.6431$ & $\chi^{2}=14.8008$ & $P=0.0006$ \\
\hline \multirow[t]{4}{*}{ rs2175595 } & AA & 5 & 12 & 1 & 0 & 2 & 0 & 8 & 12 \\
\hline & AT & 74 & 74 & 5 & 47 & 63 & 21 & 142 & 142 \\
\hline & TT & 340 & 161 & 46 & 223 & 349 & 176 & 735 & 560 \\
\hline & & 20 & $P<0$ & $=7.0114$ & 0 & 3.3631 & $P=0$. & $\chi^{2}=6$ & $P=C$ \\
\hline
\end{tabular}

Table 5 Odds ratio analyses of three independent subject groups for SNPs rs2279776, rs767674 and rs2175595

\begin{tabular}{|c|c|c|c|c|c|}
\hline \multirow[b]{2}{*}{ SNP ID } & \multirow[b]{2}{*}{ Genotype } & 674 subjects & 322 subjects & 611 subjects & Total \\
\hline & & Control & Control & Control & Control \\
\hline rs2279776 & $\begin{array}{l}\text { CC+CG } \\
\text { GG (ref.) } \\
\text { OR(95\% Cl) }\end{array}$ & $\begin{array}{cr}296 & 147 \\
126 & 102 \\
1.67(1.20,2.32)\end{array}$ & $\begin{array}{cr}22 & 159 \\
30 & 111 \\
0.51 & (0.28,(0.93)\end{array}$ & $\begin{array}{lr}231 & 93 \\
183 & 104 \\
1.42(1.00,1.98)\end{array}$ & $\begin{array}{lr}548 & 399 \\
339 & 317 \\
1.28 & (1.05,1.57)\end{array}$ \\
\hline & $P$-value & 0.0021 & 0.0273 & 0.0468 & 0.0142 \\
\hline rs767674 & $\begin{array}{l}\text { GG+AG } \\
\text { AA (ref.) } \\
\text { OR( } 95 \% \mathrm{Cl})\end{array}$ & 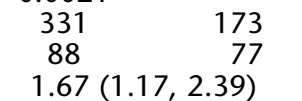 & 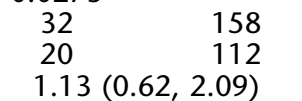 & 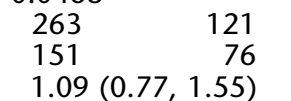 & $\begin{array}{lr}626 & 452 \\
259 & 263 \\
1.42 & (1.15,1.75)\end{array}$ \\
\hline & $P$-value & 0.0045 & 0.6851 & 0.6147 & 0.0011 \\
\hline rs2175595 & $\begin{array}{l}\text { TT } \\
\text { AA+AT (ref.) } \\
\text { OR(95\% CI) } \\
\text { P-value }\end{array}$ & $\begin{array}{cr}340 & 161 \\
79 & 86 \\
2.30(1.61, & 3.29) \\
<0.0001 & \end{array}$ & $\begin{array}{cr}46 & 223 \\
6 & 47 \\
1.62 & (0.65,2.09) \\
0.2960 & \end{array}$ & $\begin{array}{cr}349 & 176 \\
65 & 21 \\
0.64(0.38, & 1.08) \\
0.0940 & \end{array}$ & $\begin{array}{lr}735 & 560 \\
150 & 154 \\
1.35(1.05, & 1.73) \\
0.0193 & \end{array}$ \\
\hline
\end{tabular}

Case: asthma subjects; Control: nonasthma subjects; OR: odds ratio; $\mathrm{Cl}$ : confidence interval; ref.: reference genotype(s).

association between asthma phenotype and PTPRD polymorphisms was further analyzed and validated by the haplotype approach. The results of this study indicated a strong possibility that the polymorphisms of the PTPRD gene may confer risk for pediatric asthma in the Taiwanese population. Because the results of validation showed only 
weak association, further replication phases should be necessary.

Mouse PTPRD (also known as MPTP-delta) is expressed in the specialized regions of the brain and in the B-cell lineage. ${ }^{9}$ PTPRD is involved in the regulation of synaptic plasticity or in the processes regulating learning and memory in the mouse model. ${ }^{10}$ Furthermore, the results from the mouse study demonstrated that PTPRS (also known as RPTP-sigma) and PTPRD complement each other functionally during mammalian development. It also revealed that PTPRS and PTPRD played an essential role in appropriating motor neuron axon targeting during mammalian axonogenesis. ${ }^{11}$

In human disease study, PTPRD has been reported as a tumor suppressor gene. As previously reported, PTPRD is potentially involved in carcinogenesis of lung cancer, ${ }^{12-14}$ cutaneous squamous carcinomas, ${ }^{15}$ hepatomas, ${ }^{16}$ melanomas $^{17}$ and neuroblastomas. ${ }^{18}$ Though some receptor-like PTPs, such as CD45, RPTP- $\varepsilon$ and CD148, play an important role in lymphocyte activation, ${ }^{19}$ PTPRD does not demonstrate potential function to immune response as yet.

The SNP rs2279776 (C4396G) is located in exon 27 of the PTPRD gene and is a silent polymorphism. The synonymous SNP is translated to the 1418th amino acid in the first tyrosine phosphatases domain of the PTPRD protein. Codon usage for the synonymous SNP rs2279776, with GGC changed to GGG (both encode glycine), changes from $34 \%$ (frequency per thousand: 22.3 ) to $25 \%$ (frequency per thousand: 16.4; codon usage database: http:// www.kazusa.or.jp/codon/). A recent report of the Multidrug Resistance 1 (MDR1) gene indicated that silent polymorphism can change the substrate specificity. ${ }^{20}$ The SNP rs2279776 in the PTPRD gene may have a similar function as MDR1 gene's silent polymorphism, but it needs to be further elucidated.

\section{Acknowledgements}

We thank Dr Chun-Lin Su for his valuable suggestions.

\section{References}

1 Wang JY, Lin CGJ, Bey MSJ et al: Discovery of genetic difference between asthmatic children with high IgE level and normal IgE level by whole genome linkage disequilibrium mapping using 763 autosomal STR markers. J Hum Genet 2005; 50: 249-258.

2 Hunter T: Signaling-2000 and beyond. Cell 2000; 100: 113-127.

3 Puilido R, Krueger NX, Serra-Pages C, Saito H, Streuli M: Molecular characterization of the human transmembrane protein-tyrosine phosphatase delta. Evidence for tissue-specific expression of alternative human transmembrane protein-tyrosine phosphatase delta isoforms. J Biol Chem 1995; 270: 6722-6728.
4 Burney PG, Luczynska C, Chinn S, Jarvis D: The European Community Respiratory Health Survey. Eur Respir J 1994; 5: 954-960.

5 Pearce N, Sunyer J, Cheng S et al: Comparison of asthma prevalence in the ISAAC and the ECRHS. ISAAC Steering Committee and the European Community Respiratory Health Survey. International Study of Asthma and Allergies in Childhood. Eur Respir J 2000; 16: 420-426.

6 Sham PC, Curtis D: Monte Carlo tests for associations between disease and alleles at highly polymorphic loci. Ann Hum Genet 1995; 59: 97-105.

7 Gordon D, Finch SJ, Nothnagel M, Ott J: Power and sample size calculations for case-control genetic association tests when errors present: application to single nucleotide polymorphisms. Hum Hered 2002; 54: 22-33.

8 Gordon D, Levenstien MA, Finch SJ, Ott J: Errors and linkage disequilibrium interact multiplicatively when computing sample sizes for genetic case-control association studies. Pac Symp Biocomput 2003; 490-501.

9 Mizuno K, Hasegawa K, Category T, Ogimoto M, Ichikawa T, Yakura H: MPTP delta, a putative murine homolog of HPTP delta, is expressed in specialized regions of the brain and in the B-cell lineage. Mol Cell Biol 1993; 13: 5513-5523.

10 Uetani N, Kato K, Ogura H et al: Impaired learning with enhanced hippocampal long-term potentiation in PTPdelta-deficient mice. EMBO J 2000; 19: 2775-2785

11 Uetani N, Chagnon MJ, Kennedy TE, Iwakura Y, Tremblay ML: Mammalian motoneuron axon targeting requires receptor protein tyrosine phosphatases sigma and delta. J Neurosci 2006; 26: $5872-5880$

12 Nagayama K, Kohno T, Sato M, Arai Y, Minna JD, Yokota J: Homozygous deletion scanning of the lung cancer genome at a 100-kb resolution. Genes Chromosomes Cancer 2007; 46: $1000-1010$

13 Sato $\mathrm{M}$, Takahashi $\mathrm{K}$, Nagayama $\mathrm{K}$ et al: Identification of chromosome arm $9 p$ as the most frequent target of homozygous deletions in lung cancer. Genes Chromosomes Cancer 2005; 44: 405-414.

14 Zhao X, Weir BA, LaFramboise T et al: Homozygous deletions and chromosome amplifications in human lung carcinomas revealed by single nucleotide polymorphism array analysis. Cancer Res 2005; 65: 5561-5570.

15 Purdie KJ, Lambert SR, Teh MT et al: Allelic imbalances and microdeletions affecting the PTPRD gene in cutaneous squamous cell carcinomas detected using single nucleotide polymorphism microarray analysis. Genes Chromosomes Cancer 2007; 46: 661-669.

16 Urushibara N, Karasaki H, Nakamura K, Mizuno Y, Ogawa K, Kikuchi K: The selective reduction in PTPdelta expression in hepatomas. Int I Oncol 1998; 12: 603-607.

17 Stark M, Hayward N: Genome-wide loss of heterozygosity and copy number analysis in melanoma using high-density single-nucleotide polymorphism arrays. Cancer Res 2007; 67: $2632-2642$

18 Stallings RL, Nair P, Maris JM et al: High-resolution analysis of chromosomal breakpoints and genomic instability identifies PTPRD as a candidate tumor suppressor gene in neuroblastoma. Cancer Res 2006; 66: 3673-3680.

19 Mustelin T, Vang T, Bottini N: Protein tyrosine phosphatases and the immune response. Nat Rev Immunol 2005; 5: 43-57.

20 Kimchi-Sarfaty C, Oh JM, Kim IW et al: A 'silent' polymorphism in the MDR1 gene changes substrate specificity. Science 2007; 315: $525-528$.

Supplementary Information accompanies the paper on European Journal of Human Genetics website (http://www.nature.com/ejhg) 